\title{
Australian Journal of Crop Science \\ Application of floating culture system in chili pepper (Capsicum annum L.) during prolonged flooding period at riparian wetland in Indonesia
}

\author{
Erna Siaga ${ }^{1}$, Benyamin Lakitan ${ }^{2,3^{*}}$, Hasbi ${ }^{2,3}$, Siti Masreah Bernas ${ }^{2}$, Andi Wijaya ${ }^{2}$, Rika Lisda ${ }^{1}$, Fitri \\ Ramadhani ${ }^{1}$, Laily Ilman Widuri ${ }^{1}$, Kartika Kartika ${ }^{1}$, Mei Meihana ${ }^{1,4}$ \\ ${ }^{1}$ Graduate School, Universitas Sriwijaya, Palembang 30139, Indonesia \\ ${ }^{2}$ College of Agriculture, Universitas Sriwijaya, Inderalaya 30662, Indonesia \\ ${ }^{3}$ Research Center for Sub-optimal Lands (PUR-PLSO) Sriwijaya University, Palembang 30139, Indonesia \\ ${ }^{4}$ STIPER Sriwigama, Palembang 30137, Indonesia
}

\section{*Corresponding author: blakitan60@unsri.ac.id}

\begin{abstract}
Floating culture system (FCS) is the only feasible way for crop cultivation during high and prolonged flooding period at riparian wetlands. Objective of this research was to evaluate growth and yield of chili pepper cultivated using three different FCS during high flooding period at tropical riparian wetland. Floating rafts were constructed using used plastic bottles. Dimension of the raft was $2 \mathrm{~m} \times 1 \mathrm{~m}$ with load capacity of $60 \mathrm{~kg} \mathrm{~m}^{-2}$; therefore each raft can carry $120 \mathrm{~kg}$ dead weight of growing media and chili pepper grown on it. Chili pepper used was CK9856 variety. Three FCS treatments applied were: $P_{1}$, with gunny sack layer placed at interface between water surface and growing media; $P_{2}$, without gunny sack at the interface; and $P_{3}$, bottom part of growing media was immersed in water at 2-3 cm depth. These treatments were compared to $P_{0}$, conventionally cultivated chili pepper as control. Result of this study revealed that chili pepper cultivated using FCS $\left(P_{1}, P_{2}\right.$, and $\left.P_{3}\right)$ significantly outperformed those of conventionally cultivated $\left(P_{0}\right)$ as indicated by higher growth and yield. Among FCS treatments, $P_{2}$ produced the highest marketable yield $\left(248.9 \mathrm{~g} \mathrm{plant}^{-1}\right)$. Therefore, the $\mathrm{P}_{2}$ is recommended for cultivation of chili pepper by smallholder farmers at riparian wetlands during high and prolonged flooding period.
\end{abstract}

Keywords: biomaterial, floating raft, growth analysis, marketable yield, rural livelihood, smallholder farmers, substrate moisture, tropical vegetable.

Abbreviations: FCS_floating culture system; FWR_fruit weight ratio; LAR_leaf area ratio; LWR_leaf weight ratio; NAR_net assimilation rate; RGR_relative growth rate; RLD_root length density; RWR_root weight ratio; TLA_total leaf area; WAT_week after transplanting

\section{Introduction}

Indonesia has large acreage of riparian wetlands. However, most of these wetlands were underutilized due to unpredictable flooding behavior and/or prolonged flooding duration. During rainy season, the land could be flooded for up to six months and almost no agricultural activities were done by smallholder farmers during this flooding period (Irmawati et al., 2016). The high risk of crop loss due to flooding becomes a serious threat to smallholder farmer in this wetland ecosystem.

Islam et al. (2015) suggested smallholder farmers at riparian wetlands to adopt floating culture system (FCS) in cultivating crops during flooding period. FCS is a method for crop cultivation on floating raft constructed using biomaterials or synthetic materials. Biomaterials have been used by farmers included water hyacinth Eichhornia crassipes (Irfanullah et al., 2007) and peat-based material (Cros et al., 2007). Synthetic materials used were plastic and polystyrene panels (Orisni et al., 2010). Crops commonly used in FCS were annual leafy vegetables (Bernas et al.,
2012; Isalm and Atkins, 2007; Fallovo et al., 2009; Lin et al. 2014; Marlina et al., 2015; Tomasi et al., 2015).

Leafy vegetable crops recommended for floating agriculture are those characterized by small size canopy, short life/production cycle, shallow rooting, and adaptable to high moisture substrate. High nutritive and/or economic values will be an extra benefit. Farmers can earn income from yield of the vegetables (Hossain, 2014). Advantages of vegetable cultivation using FCS include continuous availability of water in the substrate; therefore, there is no need for watering the crops as long as bottom part of the substrate is in direct contact with water surface.

Chili pepper (Capsicum annum L.) is one of important vegetable commodities and has significant impact on livelihood of smallholder farmers (Akinbile and Yusoff, 2011). However, cultivation of chili pepper using FCS has not been intensively studied.

Objective of this research was to evaluate growth and yield of chili pepper cultivated using three different FCS during high flooding period at tropical riparian wetland in 
Indonesia. Results of this research will be used as scientific base for recommendation on sustainably intensifying food production at riparian wetlands in tropical humid climate, especially in Indonesia.

\section{Results and Discussion}

\section{Vertical and horizontal shoot growth}

Shoot growth in chili pepper followed the Sigmoid-S-Curve. Started with slow growth at early vegetative stage, then shifted to exponential growth, and finally slowing down upon entering generative stage. Vertical growth (plant height) reached its maximum at 6 weeks after transplanting (WAT); however, horizontal growth of branches continued to extent until 8 WAT as indicated by increase in canopy area. After chili pepper entered generative growth stage, number of fruits was continued to increase and each individual fruit was continued to enlarge. Their weight increased load to the flexible branches, dragged the branches down, caused plant height to decrease after 6 WAT and canopy area started to slightly shrink (if projected to horizontal plane) after 8 WAT. This pattern of growing curve was observed in all chili plants, regardless of the cultivation system implemented. Significant differences in plant height and canopy area amongst chili pepper cultivated using different FCS treatments were more pronounced during reproductive stage (Fig 1).

Differences in plant height at 6 WAT and canopy area at 8 WAT amongst chili plants cultivated with FCS and control plants were presented in Table 1. It was clear that average height of chili plants cultivated employing FCS treatments $\left(P_{1}, P_{2}\right.$, and $\left.P_{3}\right)$ were significantly higher than that of conventionally-grown control plants $\left(P_{0}\right)$. However, only $P_{1}$ was significantly larger in canopy area than that of $P_{0}$.

More vigorous growth of chili plants cultivated using FCS is related to higher and constant water availability. Contact between water surface and growing substrate ensures water availability within the rhizosphere due to upward water movement associated with hydrophilic nature of the growing substrate. This system is using similar principle to wicking hydroponic system (Datta, 2015; Semananda et al., 2016). Garcia and Mendoza (2008) reported that high soil or substrate water content increased shoot growth, but excessive water condition could limit root growth.

Plant height and canopy area were important parameter for determining vegetative growth in chili pepper (Narkhede et al., 2011; Chowdhury et al., 2015; El-Bassiony et al., 2010; Khan et al., 2012). Vegetative growth of chili pepper increased significantly during period of 5-8 WAT but decelerated during fruit development stage. Bhuvaneswari et al. (2013) reported that plant height rapidly increased until early flowering. True dichotomous branching pattern of chili pepper led to more flower buds developed at separating position of the two newly developing branches. Singh and Pandey (2014) noted that during fruit development stages, more new flower buds also continued to develop.

\section{Root growth and effect of water saturated layer}

Roots of chili pepper were concentrated within non-watersaturated layer of growing substrate as shown in Fig 2 . The chili pepper grown using FCS developed short but heavily branching roots as opposed to conventionally cultivated chili pepper which generated much longer roots but developed less branches. Short roots in the FCS were sufficient for balancing water losses through leaf transpiration and water uptake by heavily branching roots under high substrate moisture content. Soil moisture contents of growing substrate in $P_{1}$ and $P_{2}$ were almost doubled and $P_{3}$ was almost tripled that of $\mathrm{P}_{0}$ (Fig 3 ).

Kulkani and Phalke (2009) reported that longer roots in chili pepper often related to drought stress condition. Deeper root penetration in soil or other growing substrate has been observed in many crops as survival mechanism in water shortage condition. Under this condition, generally moisture content is relatively higher at deeper soil layers Heavily branching roots observed in the FCS is a mechanism of chili plants to maximize water absorption by increasing total root surface in a limited rhizosphere. Von Felten and Schmid (2008) found that root segregation was more important than root depth in studying root distribution, especially if the study was correlated with water availability (Proffitt et al., 1985) and root water uptake in growing substrate (Green and Clothier, 1999).

Ratio of total root weight to root length of the same plant is commonly used parameter in root study, known as root length density (RLD). The RLD was frequently associated with strategic adaptation of roots in deficient or excessive water condition (Coelho and Or, 1999). The RLD can be calculated based on fresh weight (RLDf) or dry weight (RLDd). Our results indicated that both RLDf and RLDd at 2 WAT during early vegetative growth stage were not significantly different amongst treatments (Table 2). As chili pepper growth progressing, the RLDf and RLDd values were increasing in all treatments. At 7 WAT, The RLDf values of chili pepper cultivated using FCS $\left(P_{1}, P_{2}\right.$, and $\left.P_{3}\right)$ were more than double the RLDf of conventionally cultivated chili pepper $\left(P_{0}\right)$. Differences in the RLDd values between chili peppers cultivated employing FCS and control were not as clear as in the RLDf values.

\section{Growth analysis}

Growth parameters at selected weeks for representing developmental phases of chili pepper cultivated using the FCS and conventional systems were presented in Table 3. RGR and NAR values in all cultivation systems were relative similar at the early flowering stage. The differences in RGR occurred during end of flowering stage where $P_{3}$ displayed the highest RGR and NAR compared to the other three cultivation systems which have relatively similar values. However, at the end of harvesting period, RGR and NAR of $P_{1}$ and $P_{2}$ surpassed those of $P_{0}$ and $P_{3}$.

Relative growth rate (RGR) was faster during vegetative stage at earlier weeks and then gradually declined after chili pepper reached peak of flowering period. Net assimilation rate (NAR) sharply dropped at late harvesting period. Interestingly, leaf area ratio (LAR) declined after entering reproductive growth stage but bounced back at the end of harvesting period (Fig 4). Rebound of LAR was related to new leaves development after about half of fruits were harvested. Villar et al. (2005) reported that RGR and NAR were more regulated by physiological activities (photosynthesis and respiration) while LAR was more 
Table 1. Differences in plant height at 6 WAT and canopy area at 8 WAT in chili pepper plant cultivated using floating culture system (FCS) and conventional cultivation.

\begin{tabular}{lllll}
\hline Cultivation System & Height $(\mathrm{cm})$ & \multicolumn{3}{c}{ Canopy Area $\left(\mathrm{dm}^{2}\right)$} \\
\hline $\mathrm{P}_{0}$ & 61.317 & $\mathrm{a}^{2}$ & 34.42 & $\mathrm{a}$ \\
$\mathrm{P}_{1}$ & 72.150 & $\mathrm{~b}$ & 49.15 & $\mathrm{~b}$ \\
$\mathrm{P}_{2}$ & 68.758 & $\mathrm{~b}$ & 41.17 & $\mathrm{ab}$ \\
$\mathrm{P}_{3}$ & 63.350 & $\mathrm{~b}$ & 40.03 & $\mathrm{ab}$ \\
\hline
\end{tabular}

${ }^{2}$ Means followed with the same letters within columns are not significantly different based on the LSD at $p<0.05 . P_{0}=$ conventional cultivation; $P_{1}=F C S$ with gunny sack at water-substrate interface; $P_{2}=F C S$ without gunny sack at water-substrate interface; $P_{3}=F C S$ with $2-3 \mathrm{~cm}$ bottom part of the substrate was immersed in water.
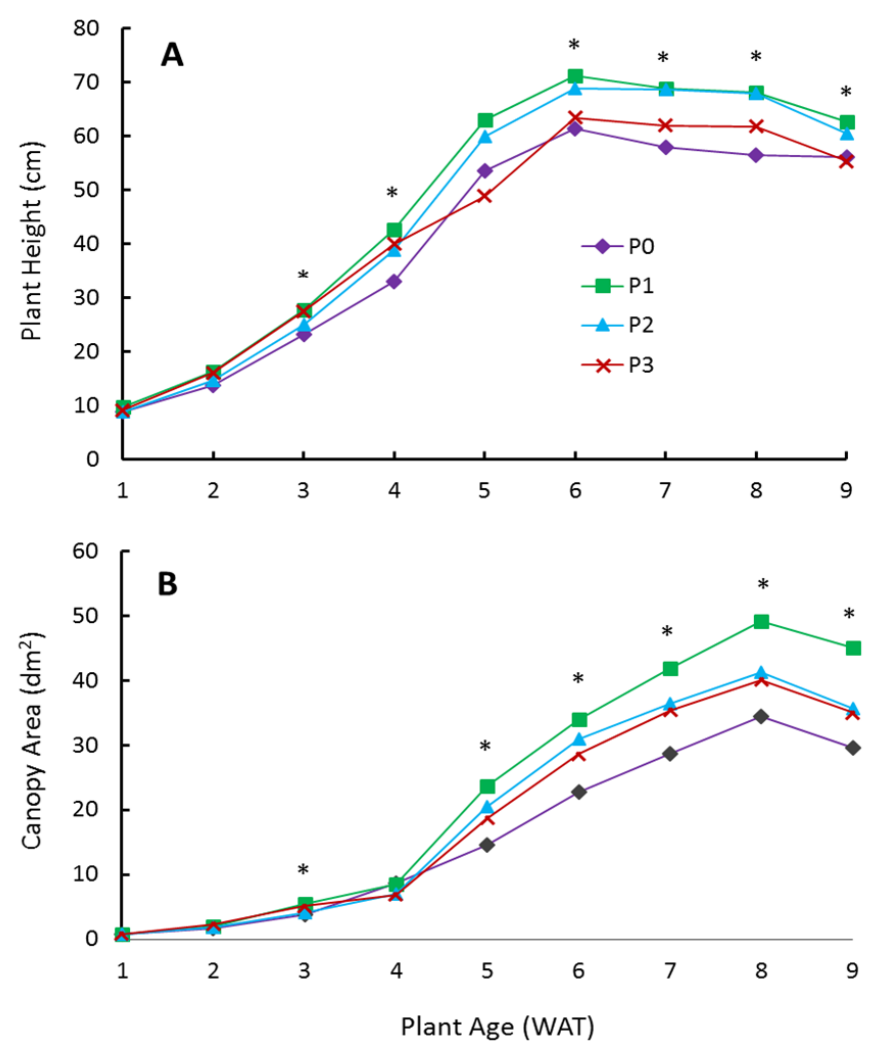

Fig 1. Comparing plant height $(A)$ and canopy area $(B)$ in chili pepper conventionally cultivated $\left(P_{0}\right)$ and using FCS $\left(P_{1}, P_{2}\right.$, and $\left.P_{3}\right)$ during nine-week period after transplanting (WAT). Significant effect of treatments at $P<0.05$ is denoted by asterisk mark $(*)$.

Table 2. Root weight to length ratio of fresh (RLDf) and dry (RLDd) in chili pepper.

\begin{tabular}{|c|c|c|c|c|}
\hline \multirow{2}{*}{$\begin{array}{l}\text { Time of Measurement } \\
\text { (WAT) }\end{array}$} & \multicolumn{4}{|l|}{ Cultivation system } \\
\hline & $\mathrm{P}_{0}$ & $\mathrm{P}_{1}$ & $\mathrm{P}_{2}$ & $\mathrm{P}_{3}$ \\
\hline & \multicolumn{4}{|c|}{ Weight/length ratio of fresh root $(\mathrm{g} / \mathrm{cm})^{\mathrm{y}}$} \\
\hline 2 & $0.027 \pm 0.013 a b^{z}$ & $0.038 \pm 0.013 a$ & $0.022 \pm 0.009 \mathrm{~b}$ & $0.031 \pm 0.009 a b$ \\
\hline 3 & $0.062 \pm 0.034 b$ & $0.101 \pm 0.019 a$ & $0.066 \pm 0.016 b$ & $0.112 \pm 0.032 \mathrm{a}$ \\
\hline 5 & $0.257 \pm 0.050 \mathrm{~b}$ & $0.396 \pm 0.153 b$ & $0.306 \pm 0.092 b$ & $0.607 \pm 0.241 \mathrm{a}$ \\
\hline 7 & $0.550 \pm 0.169 \mathrm{~b}$ & $1.283 \pm 0.280 a$ & $1.492 \pm 0.371 \mathrm{a}$ & $1.105 \pm 0.513 a b$ \\
\hline 9 & $0.974 \pm 0.280 a$ & $1.311 \pm 0.263 a$ & $1.831 \pm 0.972 \mathrm{a}$ & $1.752 \pm 0.825 a$ \\
\hline \multirow[t]{2}{*}{14} & $1.451 \pm 0.315 b$ & $2.614 \pm 0.473 \mathrm{a}$ & $2.139 \pm 0.619 a b$ & $2.075 \pm 0.413 a b$ \\
\hline & \multicolumn{4}{|c|}{ Weight/length ratio of dry root $(\mathrm{g} / \mathrm{cm})$} \\
\hline 2 & $0.004 \pm 0.001 \mathrm{a}$ & $0.004 \pm 0.001 \mathrm{a}$ & $0.003 \pm 0.001 \mathrm{a}$ & $0.003 \pm 0.001 \mathrm{a}$ \\
\hline 3 & $0.009 \pm 0.005 a$ & $0.011 \pm 0.003 a$ & $0.008 \pm 0.002 a$ & $0.012 \pm 0.002 \mathrm{a}$ \\
\hline 5 & $0.055 \pm 0.007 b$ & $0.060 \pm 0.024 \mathrm{a}$ & $0.079 \pm 0.027 a b$ & $0.091 \pm 0.042 \mathrm{a}$ \\
\hline 7 & $0.141 \pm 0.070 \mathrm{a}$ & $0.176 \pm 0.036 a b$ & $0.255 \pm 0.112 a$ & $0.154 \pm 0.054 \mathrm{a}$ \\
\hline 9 & $0.246 \pm 0.057 \mathrm{a}$ & $0.309 \pm 0.068 a$ & $0.353 \pm 0.124 a$ & $0.476 \pm 0.238 a$ \\
\hline 14 & $0.293 \pm 0.080 \mathrm{~b}$ & $0.679 \pm 0.249 a$ & $0.504 \pm 0.197 a b$ & $0.542 \pm 0.151 \mathrm{ab}$ \\
\hline
\end{tabular}


Table 3. Growth analysis parameters at selected growth stages in chili pepper conventionally cultivated and using floating culture system.

\begin{tabular}{|c|c|c|c|c|c|c|}
\hline \multirow{2}{*}{$\begin{array}{l}\text { Cultivation } \\
\text { system }\end{array}$} & \multicolumn{6}{|c|}{ Growth parameter $^{\mathrm{y}}$} \\
\hline & $\operatorname{RGR}\left(\mathrm{g} \mathrm{g}^{-1} \mathrm{w}^{-1}\right)$ & $\operatorname{NAR}\left(\mathrm{mg} \mathrm{cm}^{-2} \mathrm{w}^{-1}\right)$ & $\operatorname{LAR}\left(\mathrm{cm}^{2} \mathrm{~g}^{-1}\right)$ & $\operatorname{RWR}\left(\mathrm{g} \mathrm{g}^{-1}\right)$ & $\operatorname{LWR}\left(\mathrm{g} \mathrm{g}^{-1}\right)$ & FWR $\left(\mathrm{g} \mathrm{g}^{-1}\right)$ \\
\hline & \multicolumn{6}{|c|}{ Early Flowering Stage (5 WAT) } \\
\hline$P_{0}$ & $1.24 \pm 0.282 \mathrm{a}^{\mathrm{z}}$ & $16.43 \pm 4.120 \mathrm{a}$ & $156.55 \pm 25.525 b$ & $0.13 \pm 0.030 \mathrm{a}$ & $0.40 \pm 0.018 b$ & $0.01 \pm 0.002 \mathrm{a}$ \\
\hline$P_{1}$ & $1.22 \pm 0.116 a$ & $12.64 \pm 1.959 a$ & $164.02 \pm 18.150 \mathrm{a}$ & $0.09 \pm 0.021 a$ & $0.43 \pm 0.022 \mathrm{a}$ & $0.01 \pm 0.007 \mathrm{a}$ \\
\hline$P_{2}$ & $1.34 \pm 0.065 a$ & $13.12 \pm 4.651 \mathrm{a}$ & $169.22 \pm 21.691 \mathrm{a}$ & $0.10 \pm 0.055 a$ & $0.40 \pm 0.023 b$ & $0.01 \pm 0.009 a$ \\
\hline \multirow[t]{2}{*}{$P_{3}$} & $1.29 \pm 0.147 a$ & $14.29 \pm 7.319 a$ & $169.69 \pm 41.172 \mathrm{a}$ & $0.11 \pm 0.020 \mathrm{a}$ & $0.40 \pm 0.032 b$ & $0.02 \pm 0.010 a$ \\
\hline & \multicolumn{6}{|c|}{ Fruit Development Stage (9 WAT) } \\
\hline$P_{0}$ & $0.20 \pm 0.043 b$ & $9.59 \pm 0.661 b$ & $71.77 \pm 18.860 \mathrm{a}$ & $0.16 \pm 0.028 a$ & $0.16 \pm 0.035 a$ & $0.37 \pm 0.028 a$ \\
\hline$P_{1}$ & $0.16 \pm 0.051 b$ & $8.66 \pm 1.744 b$ & $65.64 \pm 16.685 a$ & $0.11 \pm 0.021 a$ & $0.14 \pm 0.017 \mathrm{a}$ & $0.42 \pm 0.042 \mathrm{a}$ \\
\hline$P_{2}$ & $0.17 \pm 0.015 b$ & $10.94 \pm 1.960 \mathrm{~b}$ & $72.85 \pm 38.724 a$ & $0.11 \pm 0.017 a$ & $0.15 \pm 0.011 a$ & $0.39 \pm 0.085 a$ \\
\hline \multirow[t]{2}{*}{$P_{3}$} & $0.45 \pm 0.065 a$ & $15.51 \pm 2.234 a$ & $52.86 \pm 10.911 \mathrm{a}$ & $0.13 \pm 0.050 \mathrm{a}$ & $0.14 \pm 0.012 \mathrm{a}$ & $0.43 \pm 0.041 \mathrm{a}$ \\
\hline & \multicolumn{6}{|c|}{ Late Harvesting Stage (14 WAT) } \\
\hline$P_{0}$ & $0.23 \pm 0.064 a b$ & $0.91 \pm 0.429 a b$ & $153.96 \pm 43.751 \mathrm{a}$ & $0.12 \pm 0.015 a$ & $0.20 \pm 0.031 \mathrm{a}$ & $0.33 \pm 0.048 b$ \\
\hline$P_{1}$ & $0.31 \pm 0.070 \mathrm{a}$ & $1.41 \pm 0.293 \mathrm{a}$ & $109.58 \pm 27.418 a$ & $0.12 \pm 0.024 a$ & $0.15 \pm 0.013 a b$ & $0.42 \pm 0.015 \mathrm{ab}$ \\
\hline$P_{2}$ & $0.31 \pm 0.038 a$ & $1.35 \pm 0.300 a b$ & $115.49 \pm 13.018 a$ & $0.10 \pm 0.039 a$ & $0.17 \pm 0.057 a b$ & $0.44 \pm 0.071 a$ \\
\hline $\mathrm{P}_{3}$ & $0.15 \pm 0.027 b$ & $0.76 \pm 0.290 \mathrm{~b}$ & $138.40 \pm 97.679 \mathrm{a}$ & $0.13 \pm 0.037 a$ & $0.12 \pm 0.040 \mathrm{~b}$ & $0.48 \pm 0.049 a$ \\
\hline
\end{tabular}

${ }^{y}$ Growth parameters were presented as means + standard of deviation. ${ }^{2}$ Means followed with the same letters within columns of each growth analysis parameter and for each growth stage were not significantly different based on the LSD at $p<0.05$.

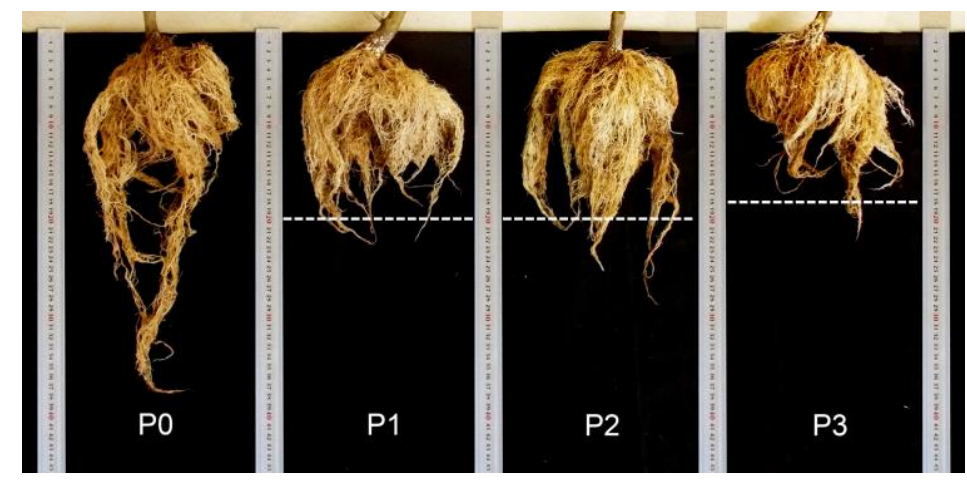

Fig 2. Roots of conventionally cultivated chili pepper $\left(P_{0}\right)$ compared to those of employing $F C S\left(P_{1}, P_{2}\right.$, and $\left.P_{3}\right)$. Broken line is the water table. Almost no root under water table was due to lack of oxygen for root aerobic metabolism at water saturated substrate.

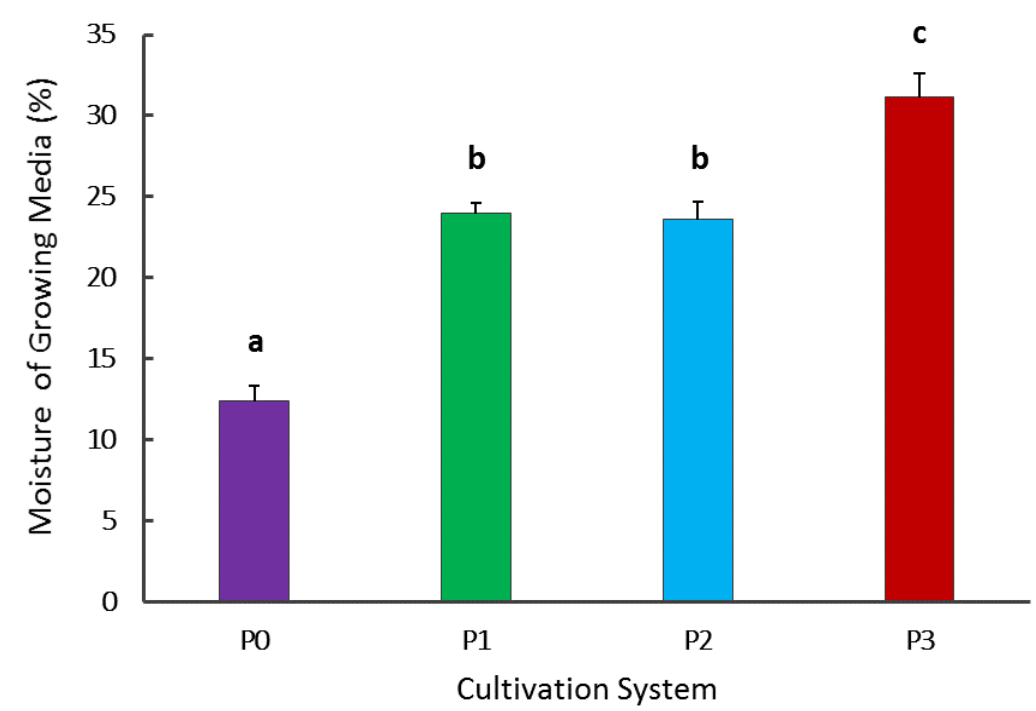

Fig 3. Moisture content differences between growing substrates used in conventional cultivation $\left(P_{0}\right)$ and using $F C S\left(P_{1}, P_{2}\right.$, and $\left.P_{3}\right)$. Statistical differences based on the LSD at $P<0.05$ among cultivation systems are indicated by different letter above the standard of deviation bar. 

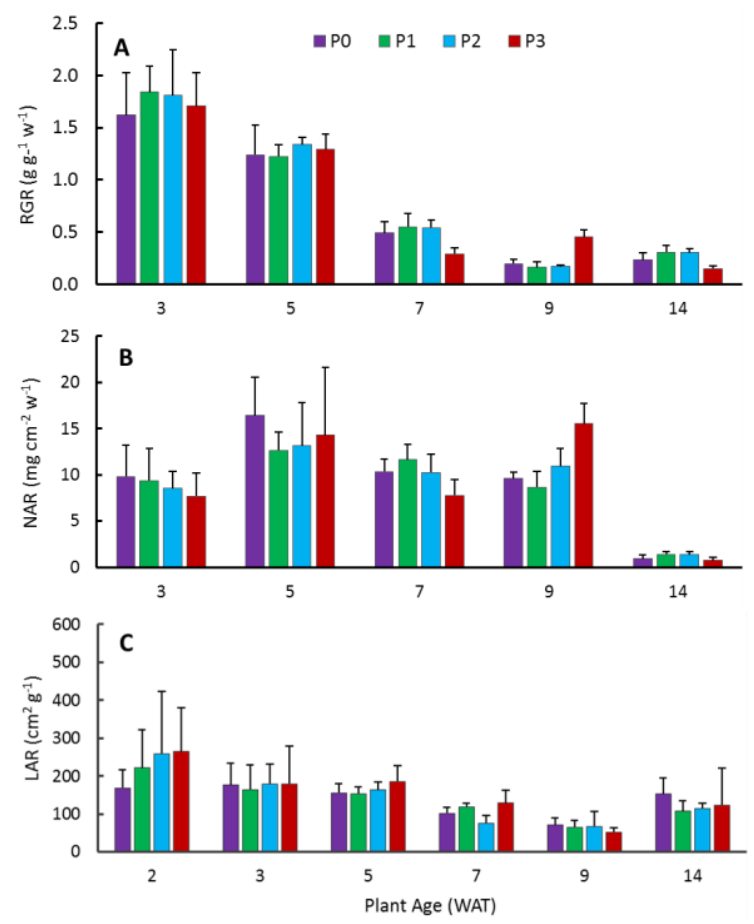

Fig 4. Relative growth rate $(A)$, net assimilation rate $(B)$, and leaf area ratio $(C)$ in chili pepper conventionally cultivated $\left(P_{0}\right)$ and using floating culture systems $\left(P_{1}, P_{2}\right.$, and $\left.P_{3}\right)$. Extended bars stand for standard of deviations. There was no significant differences among cultivation system. This figure was intended for showing the RGR, NAR, and LAR changes over time, as chili pepper grew from vegetative to generative stages.
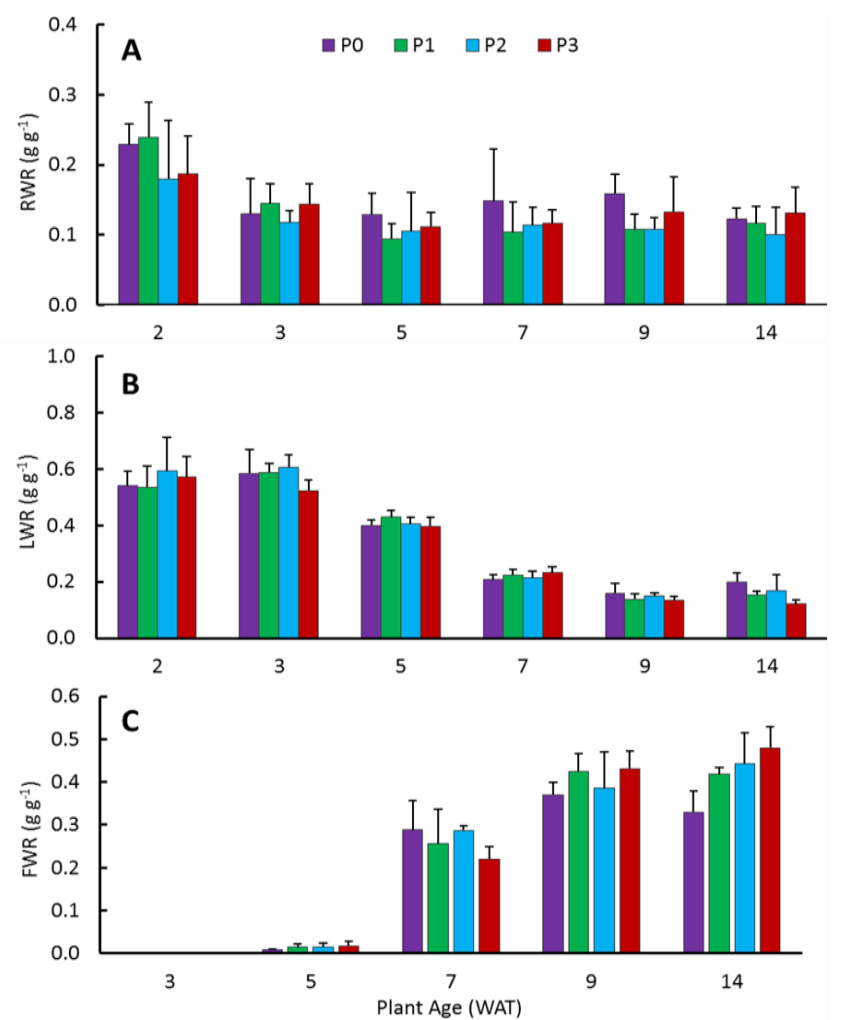

Fig 5. Root weight ratio $(A)$, leaf weight ratio $(B)$, and fruit weight ratio $(C)$ in chili pepper conventionally cultivated $\left(P_{0}\right)$ and using floating culture systems $\left(P_{1}, P_{2}\right.$, and $\left.P_{3}\right)$. Extended bars stand for standard deviations. There was no significant differences among cultivation system. This figure was intended for showing the RWR, LWR, and FWR changes as chili pepper grew from vegetative to generative stages. 

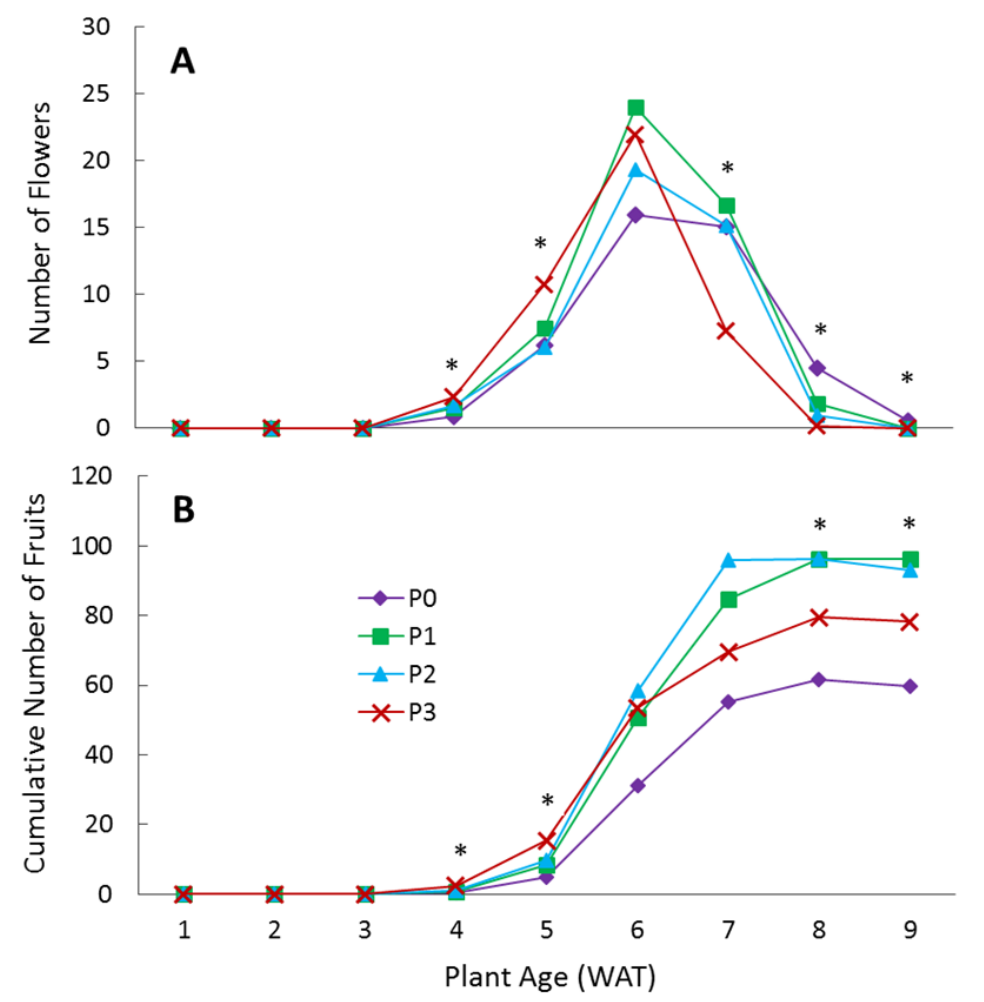

Fig 6. Number of flowers counted on a specific day during weekly observation $(A)$ and cumulative number of fruits $(B)$ in chili pepper conventionally cultivated $\left(\mathrm{P}_{0}\right)$ and using FCS $\left(\mathrm{P}_{1}, \mathrm{P}_{2}\right.$, and $\left.\mathrm{P}_{3}\right)$. Significant effect of treatments at $P<0.05$ is denoted by asterisk mark (*).
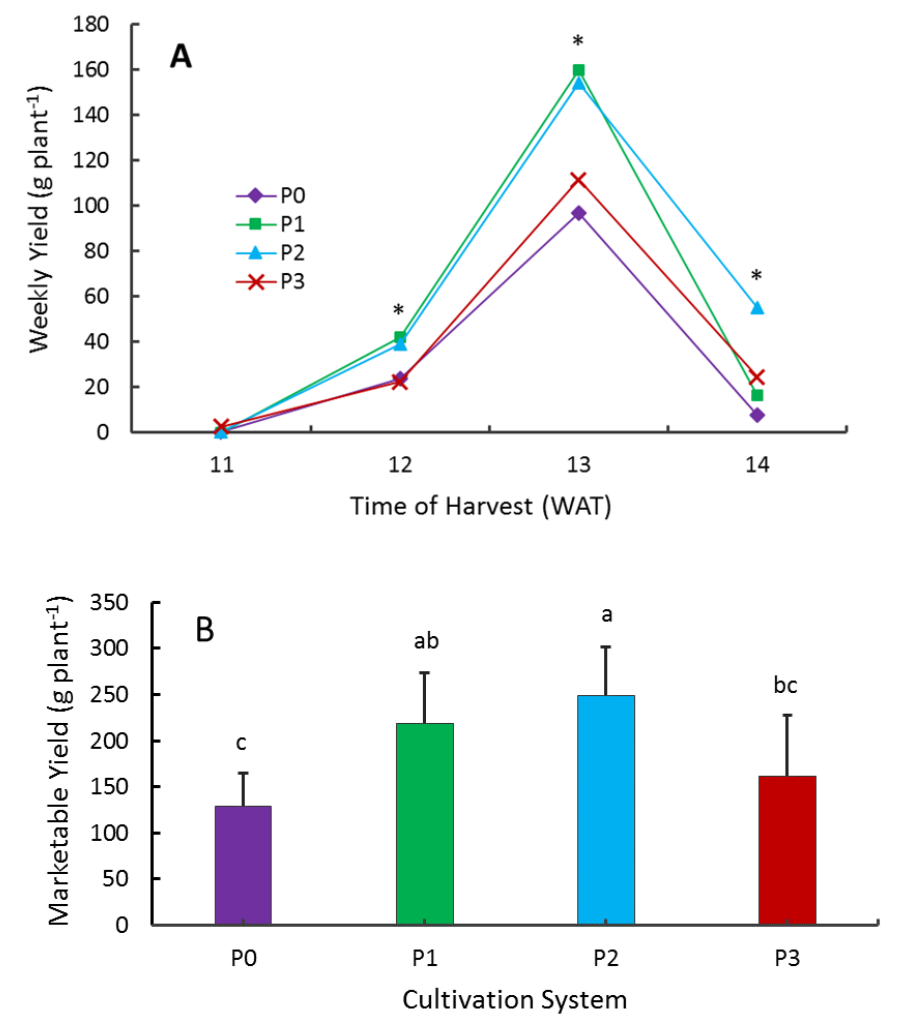

Fig 7. (A) Weekly yield of chili pepper conventionally cultivated $\left(P_{0}\right)$ and using FCS $\left(P_{1}, P_{2}\right.$, and $\left.P_{3}\right)$. Significant effect of treatments at $P<0.05$ is denoted by asterisk mark $\left({ }^{*}\right)$; (B) Comparison of cumulative marketable yield among cultivation systems. Statistical differences based on the LSD at $P<0.05$ between cultivation systems are indicated by different letter above the standard of deviation bar. 
influenced by water-related morphological and structural developments. Generally, RGR and NAR were higher at the early vegetative stage when most of leaves directly received sunlight to maximize photosynthesis. The RGR and NAR were lower at generative stage due to leaves at lower position were shaded by leaves at higher position (Masabni et al., 2016).

Decreasing of LAR after entering reproductive growth stage was associated with flower and fruit development. At this stage, more photosynthates were allocated to flowers and fruits since these organs were the stronger sinks (Amanullah et al., 2007). Rebounding of LAR at 14 WAT occurred during late harvesting. More new leaves were developed to increase photosynthetic capacity for the next cycle of reproductive organ development. It should be noted that chili pepper is a perennial crop.

Root weight ratio (RWR) was high at very early vegetative growth stage ( 2 WAT) at about 20 percent of total biomass (RWR = 0.2); thereafter, the RWR values were constant at about 15 percent. Poorter et al. (2012) reported that restricted rhizosphere affected root development. Leaf weight ratio (LWR) was higher during vegetative growth stage and then declined as fruit weight ratio (FWR) increased (Fig 5). There was a negative correlation between LWR to FWR. These results indicated that after starting of the generative stage, the chili pepper allocated more assimilates to support growth and development of reproductive organs (flower and fruit) at expense of vegetative organs (root and leaf).

\section{Reproductive growth and yield}

It was technically almost impossible to manually count cumulative number of flowers since they are short-lived. Some of flowers were aborted and others were fallen after fruits were developed; therefore, number of flowers on a specific day in the middle of each week was counted for representing relative magnitude of flowering intensity within each week from 3 to 9 WAT. There was no clear cut between flowering and fruiting phase in chili pepper, i.e. the plant continue to produce flowers during fruit development. Cumulative number of fruits was counted once in every week up to 9 WAT. Observable number of flower on selected day at mid-week and cumulative number of fruits were presented in Fig 6.

First cycle of flowering stage was occurred from 4 to 9 WAT and reached its peak at 6 WAT. Interesting to note is that $P_{3}$ plants started flowering few days earlier (2-3 days) than $P_{1}$ and $P_{2}$; while $P_{0}$ started to flower a few days later (23 days) than $P_{1}$ and $P_{2}$. Number of observable flowers was significantly different among treatments. $P_{3}$ was the highest at 4 and 5 WAT, however, was the lowest at 7 and 8 WAT. In contrast, at 8 and 9 WAT, $P_{0}$ produced the highest number of observable flowers (Fig 6).

Cumulative number of fruit reached its maximum at 8 WAT. There were significant differences among treatments at 8 and 9 WAT, i.e. $P_{1}, P_{2}$, and $P_{3}$ of FCS was higher than $P_{0}$ as control in cumulative number of fruits (Fig 6). Costa and Gianquinto (2002) reported that water availability was critical during fruit set and maturing process of fruits.

Harvesting period of chili pepper took 4 weeks or longer, but yield was sharply declined after the peak harvest at 13 WAT (Fig 7). The FCS with and without additional gunny sack ( $P_{1}$ and $\left.P_{2}\right)$ exhibited significantly higher marketable yields than conventional cultivation system $\left(P_{0}\right)$ (Fig 7). Main noticeable different between the treatments was substrate water content, i.e. continuous water availability regardless of climatic condition was an advantage in the FCS. Number of harvested fruits followed similar pattern of total yield, implying that fruit size was indifferent regardless of cultivation systems.

Water availability could give tremendous positive impacts on growth and yield (Chalkoo et al., 2014; Akinbile and Yusoff, 2011; Ismail, 2010). Water has many functions in living cells. Reduction in substrate water content led to decrease in water uptake by roots, decreased in leaf water content, and furthermore, it reduced stomatal conductance, transpiration rate, and assimilation rate in plant (Chastain et al., 2014).

Water-absorbing biomaterials (gunny sack), placed at the interface between raft upper surface and water surface, was initially applied to enhance water diffusion to the growing substrate such that moisture content in the substrate would constantly near optimal level for growth and development in chili plants. Therefore, the plants were expected to produce higher yields. Based on our results, however, growth and yield of the chili plants on the FCS with gunny sacks were not significantly higher than those without gunny sacks. Therefore, use of gunny sacks in the FCS was not recommended.

\section{Materials and methods}

\section{Plant materials}

Hybrid cultivar of CK9856 was used in this study. Seeds were soaked for approximately 8 hours in water to identify and remove the low-quality seeds. Potentially viable seeds were placed on and covered with wet cloth for germination. Germinated seeds (with visible radicle) were sown in seedling trays. Four-week-old seedlings were transplanted into black polyethylene bags (polybags) filled with mixed growing media of soil:manure:rice husk (1:1:1, v/v/v). Rice husks used was those had been weathered for more one month at outdoor condition, light weight, highly hydrophilic, had ability to retained water, and locally available. These properties make rice husk a good material to add to substrate mix for the FCS.

\section{Developing the raft for the Floating Culture System}

Raft for FCS was designed, constructed, and tested at a research facility in Jakabaring $\left(104^{\circ} 46^{\prime} 44^{\prime \prime} \mathrm{E} ; 3^{\circ} 01^{\prime} 35^{\prime \prime} \mathrm{S}\right)$, Palembang, Indonesia from June to September 2016. Technical dimension of the raft was $2.0 \mathrm{~m}$ (length) $\times 1.0 \mathrm{~m}$ (width) $\times 0.078 \mathrm{~m}$ (height). Floaters were consisted of 69 used $1500 \mathrm{~mL}$ plastic (polyethylene terephthalate, PET) mineral water bottles. The bottles were emptied and tightly sealed, arranged in three rows of 23 bottles, tied with fishing lines; then, wrapped with non-corrosive metal insect net. Identical plastic bottles were collected from plastic waste recycle facility. Three-quarter-inch PVC (polyvinyl chloride) pipes were used as external skeletons at all length and width sides, and for support at the bottom surface. The skeleton pipes were connected each other using elbows and T-shape 
fittings to form a close-circuit system such that the skeleton system also contributes to the buoyant force.

Fully constructed raft was tested for its stability (at evenly distributed load) and carrying capacity (buoyant force) in an outdoor experimental pool, with inner dimension of $4.00 \mathrm{~m}$ $\times 2.00 \mathrm{~m} \times 0.45 \mathrm{~m}$. The pool was filled with water to $40 \mathrm{~cm}$ height. In the FCS, it is crucial that upper surface of the raft at the same or slightly (up to $3 \mathrm{~mm}$ ) below water level, for making sure that bottom part of growing media is in direct contact with water. After testing, by gradually increasing load while keeping it at even load distribution, the raft was proven to have the ability to withstand weight of $123.9 \mathrm{~kg}$ at leveled position between upper raft surface and water surface (floating height $=0$ ).

\section{Floating Culture System of chili pepper}

Nine floating rafts were placed in three outdoor experimental pools, i.e. three rafts in each pool. Twenty four polybags, each was filled with $8.5 \mathrm{~kg}$ of the mixed media at optimal moisture holding capacity and one 4-week old chili pepper seedling was grown on it, were placed on each floating raft. The seedlings were selected from seedling stocks for establishing homogenous population before treatments were applied.

Four treatments applied, including $\mathrm{P}_{0}$, conventional nonfloating control; $P_{1}, F C S$ with additional water-absorbing gunny sack layer placed at interface between water surface and bottom of growing media; $P_{2}$, FCS without the gunny sack at interface between raft upper surface and water surface; and $\mathrm{P}_{3}$, FCS with raft upper surface was positioned 2-3 $\mathrm{cm}$ below water surface, i.e. bottom of growing media was immersed $2-3 \mathrm{~cm}$ in water. Direct contact between growing media and water was maintained and regularly checked for all polybags of FCS treatments.

Growth parameters were measured at 2, 3, 5, 7, 9, and 14 WAT and yield parameters were collected continuously every 2 days during harvesting period of 11 to 14 WAT. For growth analysis, sampled plants were partitioned into three parts (root, stem, leaf) during vegetative growth phase and five parts (with additional of flower and fruit) during reproductive growth phase. Fresh weight was immediately measured after separation. Non-destructive leaf area estimation was based on zero-intercept regression model of $\mathrm{LA}=0.606$ LW (Lakitan et al., 2017). For dry weight measurement, all separated parts were dried in oven at $70^{\circ} \mathrm{C}$ for three days. Plant growth analysis was calculated based on procedures in Poorter (1989) and Hunt et al. (2002).

\section{Experimental design and statistical analysis}

Analysis of variance was conducted based on the completely randomized design and calculated using Statistical Analysis System (SAS University edition) for evaluating significance effect of cultivation systems on each of relevant growth and yield parameters. Non-destructive measurements were used six replications, but destructive measurements for growth analysis used three replications. Differences among mean values of cultivation system were evaluated using the Least Significant Differences (LSD) test at $p \leq 0.05$.

\section{Conclusion}

Based on results of this study, the FCS can be implemented in chili pepper cultivation for local smallholder farmers at riparian wetland. The growth and yield of the chili pepper cultivated using any of FCS was higher than those of conventional cultivation. Furthermore, among alternatives of FCS, better results were observed in $\mathrm{P}_{1}$ and $\mathrm{P}_{2}$, indicating that the most important principles of FCS was direct contact between growing substrate and water surface. Addition of gunny sack in $P_{1}$ did not improve growth and yield of chili pepper compared to that of FCS without the water absorbing material $\left(P_{2}\right)$. Moreover, increase of growing substrate volume in direct contact with water, by immersing 2-3 cm depth of bottom part in water, decreased growth and total yield. Our findings lead to a recommendation for applying the $P_{2}$ in chili pepper floating culture system for intensifying agricultural production during prolonged flooding period at the tropical riparian wetlands in Indonesia.

\section{Acknowledgements}

We would like to thank editor-in-chief of this journal and all of reviewers for their comments and constructive suggestions. Our appreciation also goes to our colleagues who had given their superb technical assistances and scientific insights during preparation and execution of this research at Universitas Sriwijaya. This work was supported by Program PMDSU 2016 Nomor 326/SP2H/LT/DRPM/IX /2016 and Program Penelitian Unggulan Profesi 2017 Universitas Sriwijaya (SK Rektor No.0570/UN9/PP/2017)

\section{References}

Akinbile CO, Yusoff MS (2011) Growth, yield and water use pattern of chili pepper under different irrigation scheduling and management. Asian J Agric Res. 5(2): 154163.

Amanullah, Hassan MJ, Nawab K, Ali A (2007) Response of specific leaf area (SLA), leaf area index (LAI) and leaf area ratio (LAR) of maize (Zea mays $\mathrm{L}$.) to plant density, rate and timing of nitrogen application. World Appl Sci J. 2(3): 235-243.

Bernas SM, Pohan A, Aidilfitri SN, Kurniawan E (2012) Bamboo floated-cultivation model for upland kangkong (Ipomoea reptans Poir.) in tidal lowland area. J Lahan Suboptimal. 1(2): 177-185.

Bhuvaneswari G, Sivarajani R, Reeth S, Ramakrishnan K (2013) Application of nitrogen and potassium efficiency on the growth and yield of chili Capsicum annuum L. Int J Curr Microbiol App Sci. 2(12): 329-337.

Chalkoo S, Sahay S, Inam A, Iqbal S (2014) Application of wastewater irrigation on growth and yield of chili under nitrogen and phosphorus fertilization. J Plant Nutr. 37: 1139-1147.

Chastain DR, Snider JL, Collins GD, Perry CD, Whitaker J, Byrd SA (2014) Water deficit in field-grown Gossypium hirsutum primarily limits net photosynthesis by decreasing stomatal conductance, increasing photorespiration, and increasing the ratio of dark respiration to gross photosynthesis. J Plant Physiol. 171(17): 1576-1585. 
Chowdhury MSN, Hoque F, Mehraj H, Jamal Uddin AFM (2015) Vegetative growth and yield performance of four chilli (Capsicum frutescens) cultivars. American-Eurasian J Agric Environ Sci. 15(4): 514-517.

Cros V, Martinez-Sanchez JJ, Franco JA (2007) Good yield of common purslane with a high fatty acid content can be obtained in a peat-based floating system. Hort Technol. 17(1): 14-20.

Coelho EF, Or D (1999) Root distribution and water uptake patterns of corn under surface and subsurface drip irrigation. Plant Soil. 206(2): 123-136.

Costa LD, Gianquinto G (2002) Water stress and water table depth influence yield, water use efficiency, and nitrogen recovery in bell pepper: lysimeter studies. Aust J Agr Res. 53(2): 201-210.

Datta, S (2015) Aquaponics: its present status and potential. Fishing Chimes. 34(11): 44-48.

El-Bassiony AM, Fawzy ZF, Abd El-Samad EH, Rias GS (2010) Growth, yield and fruit quality of sweet pepper plants (Capsicum annuum L.) as affected by potassium fertilization. J Am Sci. 6(12): 722-729.

Fallovo C, Rouphael Y, Rea E, Battistelli A, Colla G (2009) Nutrient solution concentration and growing season affect yield and quality of Lactuca sativa L. var. acephala in floating raft culture. J Sci Food Agr. 89(10): 1682-1689.

Garcia I, Mendoza R (2008) Deficit and excess of soil water impact on plant growth of Lotus tenuis by affecting nutrient uptake and arbuscular mycorrhizal symbiosis. Plant Soil. 304: 117-131.

Green S, Clothier B (1999) The root zone dynamics of water uptake by a mature apple tree. Plant Soil. 206: 61-77.

Hossain MA (2014) Floating Cultivation: an indigenous technology for adapting to water logging situation towards sustainable livelihood security in the low lying areas of Bangladesh. J Biosci Agric Res. 1(1): 54-58.

Hunt R, Causton, DR, Shipley B, Askew AP (2002) A modern tool for classical plant growth analysis. Ann Bot. 90(4): 485-488.

Irfanullah HM, Adrika A, Ghani A, Khan ZA, Rashid MA (2008) Introduction of floating gardening in the north-eastern wetlands of Bangladesh for nutritional security and sustainable livelihood. Renew Agr Food Syst. 23(2): 89-96.

Irmawati, Ehara H, Suwignyo RA, Sakagami J (2015) Swamp rice cultivation in South Sumatera, Indonesia: on Overview. Trop Agr Develop. 59(1): 35-39.

Isalm T, Atkins PJ (2007) Indigenous floating cultivation: a sustainable agricultural practice in the wetlands of Bangladesh. Development in practice. 17(1): 130-136.

Islam MA, Kamruzzaman M, Akter A, Roy PC (2015) Perception of haor farmers about the innovative features of floating farming. Int J Nat Soc Sci. 2(4): 52-58.

Ismail SM (2010) Influence of deficit irrigation on water use efficiency and bird pepper production (Capsicum annuum L.). JKAU: Met Environ Arid Land Agric Sci. 21(2): 29-43.

Khan Z, Tiyagi SA, Mahmood I, Rizvi R (2012) Effects of N fertilization, organic matter, and biofertilizers on the growth and yield of chili in relation to management of plant-parasitic nematodes. Turk J Bot. 36: 73-81.
Kulkani M, Phalke S (2009) Evaluating variability of root size system and its constitutive traits in hot pepper (Capsicum annum L.) under water stress. Sci Hortic. 120: 159-166.

Lakitan B, Widuri LI, Meihana M (2017) Simplifying procedure for a non-destructive, inexpensive, yet accurate trifoliate leaf area estimation in snap bean (Phaseolus vulgaris). J Appl Hort. 19(1): 15-21.

Lin Q, Feng X, Huang W, Cai L, Wang Y, Xu B, Dai Y (2014) Research progress on application of Ipomoea aquatic floating bed in eutrophication water. Meteorol Environ Res. 5(10): 52-55.

Marlina N, Syafullah, Aminah RIS, Gusmiatun, Rosmiah, Midranisiah, Purwanti Y, Gribaldi (2015) Floating agriculture system using plastic waste for vegetables cultivation at swamp area. Int J Eng Res Sci Tech. 4(2): 101111.

Masabni J, Sun Y, Niu G (2016) Shade effect on growth and productivity of tomato and chili pepper. Hort Technol. 26(3): 344-350.

Narkhede SD, Attade SB, Ingle ST (2011) Study on effect chemical fertilizer and vermicompost on growth of chili pepper plant (Capsicum annum). J Appl Sci Environ Sanitation. 6(3): 327-332.

Orsini F, Fecondini M, Mezzetti M, Michelon N, Gianquinto G (2010) Simplified hydroponic floating systems for vegetable production in Trujillo, Peru. In Gianquinto G, Orsini $F$ (eds) ISHS'2010: topics in acta horticulturae. 2rd international conference on landscape and urban horticulture, June 2009.

Poorter H (1989) Plant growth analysis: towards a synthesis of the classical and the functional approach. Physiol Plantarum. 75: 237-244.

Poorter H, Buhler J, Van Dusschoten D, Climent J, Postma JA (2012) Pot size matters: a meta-analysis of the effects of rooting volume on plant growth. Funct Plant Biol. 39: 839850.

Proffitt APB, Berliner PR, Oosterhuis DM (1985) A comparative study of root distribution and water extraction efficiency by wheat grown under high-and lowfrequency irrigation. Agron J. 77(5): 655-662.

Semananda NPK, Ward JD, Myers BR (2016) Evaluating the efficiency of wicking bed irrigation systems for small-scale urban agriculture. Horticulturae. 2(4): 13.

Singh AK, Pandey AK (2014) Dynamics of anthracnose disease of chili in responses to water and nitrogen management under drip and flood irrigation. J AgriSearch. 1(3): 151-156.

Tomasi N, Pinton R, Costa LD, Cortella G, Terzano R, Mimmo T, Scampicchio M, Cesto S (2015) New 'solutions' for floating cultivation system of ready-to-eat salad: a review. Trends Food Sci Tech. 30: 1-10.

Villar R, Maranon T, Quero JL, Panadero P, Arenas F, Lambers $H$ (2005) Variation in relative growth rate of 20 Aegilops species (Poaceae) in the field: the importance of net assimilation rate or specific leaf area depends on the time scale. Plant Soil. 272: 11-27.

Von Felten S, Schmid B (2008) Complementarity among species in horizontal versus vertical rooting space. J Plant Ecol. 1(1): 33-41. 